GUILHERME JARDIM JURKSAITIS

\title{
UMA PROPOSTA DE RELEITURA PARA O DIREITO AO EQUILÍBRIO ECONÔMICO-FINANCEIRO NOS CONTRATOS ADMINISTRATIVOS
}

TESE DE DOUTORADO

Orientador: Professor Titular Dr. Fernando Dias Menezes de Almeida

UNIVERSIDADE DE SÃO PAULO

FACULDADE DE DIREITO

São Paulo - SP 
GUILHERME JARDIM JURKSAITIS

\title{
UMA PROPOSTA DE RELEITURA PARA O DIREITO AO EQUILÍBRIO ECONÔMICO-FINANCEIRO NOS CONTRATOS ADMINISTRATIVOS
}

\begin{abstract}
Tese de Doutorado apresentada à Banca Examinadora na Faculdade de Direito da Universidade de São Paulo, como exigência parcial para obtenção do título de Doutor em Direito, sob a orientação do Professor Titular Dr. Fernando Dias Menezes de Almeida.
\end{abstract}

UNIVERSIDADE DE SÃO PAULO

FACULDADE DE DIREITO

São Paulo - SP

2019 
BANCA EXAMINADORA

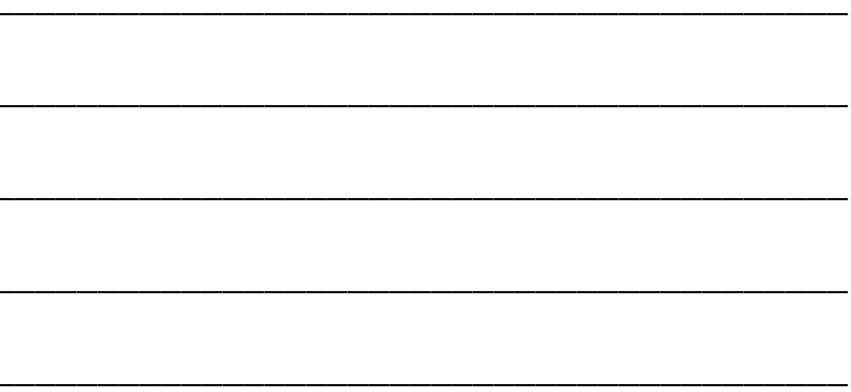


Para Aida Jardim, Cláudio Jurksaitis, Ivan Cesar Jardim e Mariana Jardim, com muito amor e infinita gratidão. 


\section{RESUMO}

JURKSAITIS, Guilherme Jardim. Uma proposta de releitura para o direito ao equilíbrio econômico-financeiro nos contratos administrativos. 2019. 153 p. Tese (Doutorado) - Faculdade de Direito, Universidade de São Paulo, São Paulo, 2019.

Esta tese de doutorado tem por objetivo apresentar uma proposta de releitura para o direito ao equilíbrio econômico-financeiro nos contratos administrativos. A questão central é saber se o conceito atualmente vigente para o direito ao equilíbrio econômico-financeiro, no direito positivo e na doutrina, é adequado para lidar com as características de complexidade e mutabilidade dos contratos de concessão de serviços públicos.

Para analisar este tema, o trabalho parte da construção do tema do contrato administrativo no direito francês, passando, em seguida, para a análise da sua recepção pela doutrina e legislação brasileiras. Após, verifica-se a forma como o tema do equilíbrio econômicofinanceiro é tratado no Brasil, especialmente pela doutrina e pelas leis de licitação e de concessões.

$\mathrm{Na}$ sequência, defende-se a insuficiência do tratamento dado ao tema pela doutrina majoritária, o que suscita a necessidade de uma releitura para o tema.

A tese defende que o equilíbrio econômico-financeiro seja considerado de acordo com as seguintes diretrizes: (i) é necessário que o tema seja analisado de acordo com a complexidade e a mutabilidade inerentes a tais contratos; (ii) eventos que aumentem os ônus do concessionário, derivados de fato do príncipe e da teoria da imprevisão, não obrigatoriamente levam ao dever de a Administração concedente arcar integralmente com os custos de tais fatos.

A tese sugere que é preciso reconhecer às partes, nos contratos de concessão, espaço para a repactuação do contrato em casos de ocorrência de eventos abrangidos pelas teorias do fato do príncipe e da imprevisão.

Palavras-chave: contratos administrativos; concessão de serviços públicos; teoria da imprevisão; fato do príncipe; equilíbrio econômico-financeiro. 


\begin{abstract}
JURKSAITIS, Guilherme Jardim. A proposal for the reinterpretation of the right to economic and financial balance in administrative agreements. 2019. 153 p. Thesis (Doctorate) - Law School, Universidade de São Paulo, São Paulo, 2019.
\end{abstract}

The aim of this doctorate thesis is to present a proposal for the reinterpretation of the right to economic and financial balance in administrative agreements. The central issue is to establish whether the current concept of the right to economic and financial balance, in substantive law and in legal doctrine, can adequately deal with the complex and changeable nature of agreements for the concession of public services.

In analyzing the issue, this study starts by considering the definition of the administrative agreement under French law, and then observing how it has been transferred into Brazilian legal doctrine and legislation. After that we shall look at the way in which the matter of economic and financial balance is treated in Brazil, in particular in jurisprudence and in the laws governing bidding and concessions.

I shall then argue that the issue has been insufficiently addressed by the majority of the jurisprudence, and that therefore a reinterpretation is needed.

I shall argue that economic and financial balance should be considered in accordance with the following guidelines: (i) it is necessary for an analysis of the subject to take account of the complex and changeable nature of these agreements; (ii) events that add to the costs for the concessionaire, derived from the factum principis or unpredictability theory, do not necessarily lead to a duty of the granting authority to bear all such costs.

The argument suggests that concession agreements should give the parties the freedom to renegotiate if such events occur.

Key words: administrative agreements; concession of public services; unpredictability theory; factum principis; economic and financial balance. 


\section{RÉSUMÉ}

JURKSAITIS, Guilherme Jardim. Une proposition de relecture pour le droit à l'équilibre financière dans les contrats administratifs. 2019. 153 p. Thèse (Doctorat) Faculté de Droit, Université de São Paulo, São Paulo, 2019.

L'objectif de cette thèse est de proposer une proposition de relecture pour le droit à l'équilibre financière dans les contrats administratifs. La question essentielle est de savoir si la conception en vigueur pour ce droit, dans le droit positif et la doctrine, est approprié pour faire face à la complexité et la mutabilité des contrats de concession des services publics.

Afin de l'analyser ce thème, le travail d'abord étudie la formation du contrat administratif dans le droit français, et, ensuite, sa réception pour la législation et la doctrine brésiliennes. Après, il est étudié comme le sujet de l'équilibre financière est abordé au Brésil, surtout par la doctrine et les lois de marchés publics et de concession des services publics.

Par la suite, on soutient la faiblesse de la doctrine consolidée dans ce thème, ce qui suscite la nécessité d'une relecture de ce thème.

La thèse soutient que l'équilibre financière soit entendu selon les directives suivantes : (i) il faut que le thème soit analysé selon la complexité et la mutabilité des contrats des concession des services publics; (ii) les événements qui accroissent les fardeaux du concessionnaire, provenant de la théorie du fait du prince et de l'imprévision, n'entraînait pas nécessairement au besoin de l'Administration prendre en charge l'intégralité des frais correspondants.

La thèse indique qu'il faut fournir aux parties des contrats des concessions les moyens juridiques pour la révision du contrat, dans les cas où il est frappé pour les événements caractérisés comme inclus dans les théories du fait du prince et de l'imprévision.

Mots-clés: contrats administratifs; concession des services publics; théorie de l'imprévision; théorie du fait du prince; équilibre financière. 


\section{SUMÁRIO}

APRESENTAÇÃ 0 .............................................................................................................. 10

NOTA METODOLÓGICA ..........................................................................................16

CAPÍTULO 1 - CONTRATO ADMINISTRATIVO......................................................20

1. A influência do direito administrativo francês no Brasil............................................2 20

2. A jurisprudência do Conselho de Estado francês e as origens do conceito de contrato administrativo.

3. A contribuição de Gaston Jèze para o conceito de contrato administrativo, na França e no Brasil

CAPÍtUlO 2 - CONSIDERAÇÕES GERAIS SOBRE CONTRATOS ADMINISTRATIVOS NO BRASIL ........................................................................................41

1. O traço de instabilidade dos contratos administrativos ......................................... 41

2. A garantia da manutenção do equilíbrio econômico-financeiro................................49

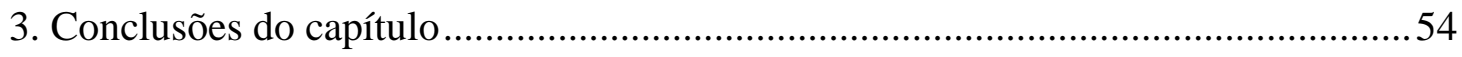

CAPÍTULO 3 - EQUILÍBRIO ECONÔMICO-FINANCEIRO NA DOUTRINA

BRASILEIRA........................................................................................................................55

1. Desenvolvimento histórico do direito ao equilíbrio econômico-financeiro na

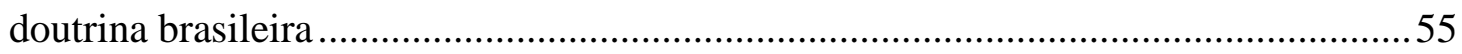

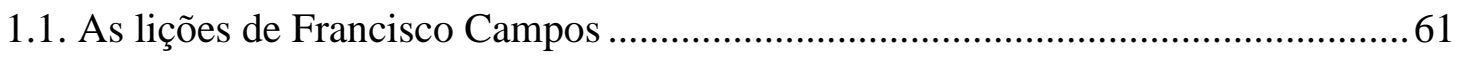

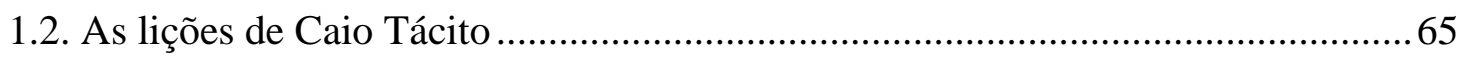

2. Equilíbrio econômico-financeiro na lei de licitações ............................................. 74

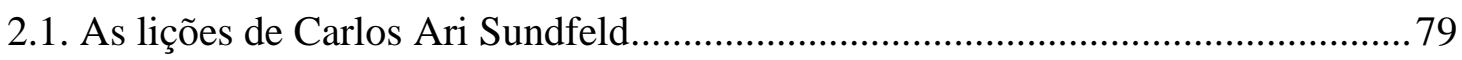

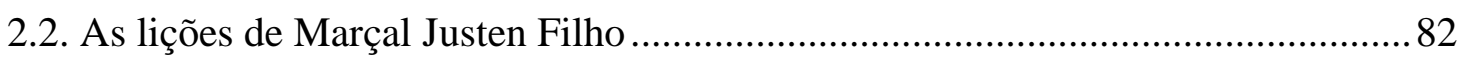

2.3. As lições de Floriano de Azevedo Marques Neto e Carlos Eduardo Cunha .......... 86

2.4. As lições de Egon Bockmann Moreira ................................................................ 91

2.5. A opinião de Marcos Augusto Perez .......................................................................95 
3. Conclusões do capítulo. 101

CAPÍTUlO 4 - PROPOSTA DE RELEITURA DO EQUILÍbRIO ECONÔMICO FINANCEITO NOS CONTRATOS ADMINISTRATIVOS............................................103

1. As diferentes lógicas dos contratos regidos pela lei de licitações e pela lei de concessão

2. Insuficiência das normas gerais sobre equilíbrio econômico-financeiro em contratos complexos

CAPÍTULO 5 - REVISÃO DO EQUILÍBRIO ECONÔMICO-FINANCEIRO NAS CONCESSÕES DE RODOVIAS PAULISTAS.

1. Apresentação do caso das Concessões Rodoviárias do Estado de São Paulo 125

2. Da celebração dos contratos de concessão rodoviária 127

3. Dos eventos de desequilíbrio 129

4. Da metodologia adotada para a quantificação do desequilíbrio e sua recomposição

5. Do questionamento administrativo a respeito da validade dos termos aditivos ..... 136

6. Do questionamento judicial a respeito da validade dos termos aditivos 139 


\section{APRESENTAÇÃO}

A escolha do tema do presente trabalho nasceu de uma experiência concreta. No ano de 2012, prestes a concluir o seu mestrado nesta Faculdade, o candidato presidiu comissão administrativa instaurada pela Agência Reguladora de Serviços Públicos Delegados de Transportes do Estado de São Paulo - ARTESP, com o fito de analisar o equilíbrio econômico-financeiro de contratos de concessão firmados nos anos de 1998 a 2002, entre o Governo do Estado de São Paulo e concessionárias privadas de rodovias.

Em breve síntese, o problema examinado derivava de aditamentos firmados no ano de 2006 entre o Governo do Estado e as concessionárias, por intermédio dos quais se reconheceu a ocorrência de eventos de desequilíbrio econômico-financeiro (especialmente, mudanças na localização de praças de pedágio, parcelamento de reajustes tarifários e alterações tributárias tudo posteriormente à apresentação das propostas e à assinatura dos contratos) e promoveu-se o necessário reequilíbrio, por meio da dilação do prazo contratual inicialmente fixado. O cálculo do montante a ser reequilibrado e a efetiva recomposição foram feitos tomando-se como base as propostas, e as projeções financeiras nela contidas, apresentadas pela concessionária no momento da licitação, e que foram consideradas para a assinatura do contrato.

A questão controversa por detrás da situação narrada era saber se, à luz da legislação e dos contratos assinados, seria lícita a recomposição do equilíbrio econômicofinanceiro tomando-se por base as projeções constantes da proposta - o que envolvia, inclusive, projeções de tráfego para todo o prazo original da concessão -, ao invés da demanda efetivamente verificada. A consequência prática de se adotar um ou outro parâmetro importava na quantificação do montante a ser reequilibrado, uma vez que as projeções se revelaram superiores à demanda "real", na maior parte dos contratos examinados pela comissão administrativa.

Como a remuneração das concessionárias dá-se mediante a cobrança de tarifas aos usuários, há impacto significativo, para fins de cálculo do desequilíbrio, entre a opção de se adotar projeções de demanda, fossem elas superestimadas ou não, ou a demanda efetivamente verificada. Para ilustrar os efeitos do problema, num dos casos examinados, a adoção da proposta e de suas projeções para a medição do desequilíbrio levou ao 
reconhecimento de desequilíbrio milionário em favor da concessionária, ao passo que a consideração da demanda efetivamente verificada importaria em desequilíbrio a favor do Poder Concedente.

Ao desempenhar a função de presidente da sobredita comissão administrativa, observou-se a insuficiência das normas legais e contratuais para arbitrar conflitos complexos como aquele, envolvendo o equilíbrio econômico-financeiro de contratos de concessão. A percepção era a de que a compreensão do equilíbrio econômico-financeiro limitado ao postulado da "preservação das condições efetivas da proposta", conforme se verifica do artigo 37, inciso XXI, da Constituição Federal, era - como é - insuficiente para decifrar o equilíbrio econômico-financeiro nos contratos de concessão de serviços públicos.

A hipótese do presente trabalho é a de que a adoção dessa fórmula faz pouco sentido em contratos de concessão. Se, de um lado, pode-se identificar com alguma facilidade o que é a proposta num contrato regido predominantemente pela Lei Federal $n{ }^{\circ}$ 8.666, de 21 de junho de 1993 (lei de licitações) - planilha de custos, quantitativos, prazos, condições de entrega, etc. -, de outro, é consideravelmente distinto o papel da proposta num contrato de concessão - prazos mais dilatados, ausência de quantitativos, compromissos com níveis de serviços, cronogramas de investimentos que se protraem por períodos longos, etc.

Além disso, há dificuldade prática de se identificar, em um contrato de concessão, os efeitos de dado evento de desequilíbrio e os mecanismos para sua recomposição, considerando-se tratar de contratos de longo prazo, em que as consequências de um evento de desequilíbrio podem se prolongar no tempo.

Nesse contexto, passou-se a especular e a refletir sobre o tema que ora constitui o objeto do trabalho ${ }^{1}$.

\footnotetext{
${ }^{1}$ Algumas dessas reflexões foram apresentadas em artigo anteriormente publicado, no qual este candidato elaborou análise jurídica sobre o tema do equilíbrio econômico-financeiro. A referência para o artigo é: Gustavo Andrey de Almeida Lopes Fernandes e Guilherme Jardim Jurksaitis. "Equilíbrio econômico e financeiro em contratos administrativos de longo prazo: um diálogo necessário entre advogados e economistas" in Revista de Direito Administrativo Contemporâneo, ano 4, vol. 23, mar./abr. de 2016. São Paulo: Editora Revista dos Tribunais, pp.: 83-106.
} 
No final do ano de 2013, já mestre por esta Faculdade, o candidato desligou-se de seu cargo na ARTESP e passou a ocupar a função de assessor técnico-procurador no Tribunal de Contas do Estado de São Paulo, trabalhando predominantemente com o exame de editais de licitação e com o acompanhamento da execução de contratos públicos, regidos tanto pela lei de licitações quanto pelas leis de concessões, destacando-se a Lei Federal n. ${ }^{\circ}$ 8.987, de 13 de fevereiro de 1995 (lei de concessões). Posteriormente, no ano de 2014, o caso envolvendo a ARTESP e as concessionárias de rodovias foi levado ao Poder Judiciário.

A lida na Corte de Contas reforçou a impressão inicial concernente à ausência de tratamento doutrinário, normativo e jurisprudencial adequado para o equilíbrio econômicofinanceiro, agora, de maneira ainda mais ampla, alcançando também os contratos regidos pela lei de licitações, contratos esses que não serão objeto desta tese, sem prejuízo de referências à lei de licitações, pois nessa lei é que estão positivados os parâmetros do equilíbrio econômico-financeiro.

Feito esse esclarecimento inicial, cumpre, a seguir, adiantar algo sobre a tese que se pretende desenvolver. 


\section{INTRODUÇÃO}

Como o próprio título indica, o objetivo desta tese é oferecer uma proposta de releitura para o direito ao equilíbrio econômico-financeiro nos contratos administrativos, especialmente nos de concessão de serviços públicos.

Nesse contexto, a tese avalia como o direito administrativo vem tratando do assunto no Brasil. A questão central é saber se o conceito atualmente vigente para o direito ao equilíbrio econômico-financeiro, no direito positivo e na doutrina, é adequado para lidar com as características de complexidade e mutabilidade dos contratos de concessão de serviços públicos. A impressão é a de que a resposta é negativa.

A releitura para o direito ao equilíbrio econômico-financeiro que esta tese propõe considera as origens do instituto no direito brasileiro, a partir do exame da doutrina, sem olvidar de imperativos de ordem prática, como a necessidade de se considerar as variáveis econômicas que permeiam os contratos de concessão, trazendo alguma flexibilidade para que se regulamente essa garantia em níveis infraconstitucional e contratual para além da fórmula reducionista aplicada comumente - de manutenção das "condições do contrato"2 ou das "relação que as partes pactuaram inicialmente"3.

A tese reflete, ainda, sobre as seguintes provocações, considerando-se a ocorrência de evento imprevisível ao tempo da celebração do contrato ou oferecimento da proposta (tratados de modo semelhante na presente tese), qualificáveis como teoria da imprevisão ou como fato do príncipe:

(i) Para fins de aferição do desequilíbrio contratual, deve-se considerar os termos da proposta apresentada ou os aspectos reais e concretos do contrato ao tempo da ocorrência dos fatos tidos como causadores do desequilíbrio?

(ii) Deve a Administração sempre arcar com a totalidade do prejuízo sofrido pelo particular contratado?

\footnotetext{
${ }^{2}$ Lei de Concessões. Art. 10.

${ }^{3}$ Lei de Licitações. Art. 65, I, $d$.
} 
(iii) Como considerar o equilíbrio econômico-financeiro de contrato de concessão, de acordo com a dinamicidade típica dos contratos de delegação de longo prazo?

Nesse passo, adotam-se as seguintes premissas da tese a ser desenvolvida:

(i) Entende-se por equilíbrio econômico-financeiro a manutenção das condições originais do contrato - ou da proposta, o que é indiferente para a presente tese -, respeitando-se às expectativas econômico-financeiras das partes, verificáveis naquele momento inicial de assinatura do contrato;

(ii) Eventos que provocam desequilíbrio contratual são necessariamente decorrentes de circunstâncias imprevisíveis pelas partes no momento da assinatura do contrato - ou da apresentação da proposta. Entende-se por imprevisíveis os eventos não previstos no contrato ou na proposta, e para cujas consequências a legislação ou as práticas usuais do mercado não contemplam responsabilização a nenhuma das partes do contrato, individualmente consideradas;

(iii) Consequentemente, a ocorrência efetiva de riscos contratuais, atribuídos individualmente às partes, pelo contrato, pela legislação aplicável, ou pelas práticas usuais do mercado, não é classificável como eventos de desequilíbrio; $\mathrm{e}$

(iv) Por outro lado, a ocorrência de eventos de desequilíbrio extracontratuais, aí incluídos os eventos abrangidos pela teoria da imprevisão e os de força maior, com impacto efetivo sobre o equilíbrio econômico-financeiro do contrato, enseja, necessariamente, que as partes renegociem os seus termos anteriores.

A partir destas premissas, após análise de parcela da doutrina nacional, chegou-se à tese deste trabalho, que pode ser sumarizada nas quatro proposições a seguir expostas:

(a) A garantia ao equilíbrio econômico-financeiro presta-se a proteger o particular contratado de consequências deletérias decorrentes do exercício efetivo dos poderes especiais pela Administração, enquanto parte da relação contratual. Para além disso, quanto muito, a garantia ao equilíbrio econômico-financeiro serve para proteger o particular contratado da ocorrência de fatos extracontratuais, porém, provocados pela Administração para, produzindo efeitos concretos, alterar o modo 
de ser do objeto serviço público originalmente contratado. Nesse sentido, eventos abrangidos pela teoria da imprevisão ou considerados como de força maior não são passíveis de reequilíbrio econômico-financeiro - mas devem dar ensejo à repactuação do contrato, conforme exposto a seguir.

(b) Falar-se em equilíbrio econômico-financeiro para contratos administrativos regidos pela lei de licitações não é o mesmo que se falar em equilíbrio econômico-financeiro para contratos de concessão de serviços públicos, o que impacta na extensão do direito ao equilíbrio econômico-financeiro num e noutro caso.

(c) A ocorrência de eventos extracontratuais, abrangidos pela teoria da imprevisão ou de força maior, e que impactem o equilíbrio econômico-financeiro inicial da avença, pode inviabilizar o seu restabelecimento. Nesses casos, falar-se em reequilíbrio econômico-financeiro é uma imprecisão técnica, admitida, contudo, em razão da sedimentação de seu uso para essa finalidade.

(d) A superveniência de alterações tributárias pode não dar ensejo ao exercício do direito ao equilíbrio econômico-financeiro do contrato, exceto se decorrente de ato de efeitos concretos sobre o objeto serviço público que constitui o objeto do contrato de concessão, como exposto no primeiro tópico. Alterações tributárias de efeitos abstratos, que porventura afetem os custos contratuais, não se equiparam ao exercício de poderes especiais pela Administração enquanto parte contratual. Ademais, é equivocado supor que a Administração contratante necessariamente dispõe de instrumentos ou poderes para influenciar, de modo direto, alterações tributárias de competência legislativa diversa com o fim de obter benefícios econômico-financeiros extracontratuais do particular com quem contrata.

As proposições acima listadas são arriscadas, pois contrariam o consenso teórico dominante a respeito do direito ao equilíbrio econômico-financeiro nos contratos administrativos brasileiros. A pretensão não é revolucionar a teoria atual, ou modificar a visão predominante, mas apenas oferecer algumas bases para eventual releitura do instituto. 


\section{NOTA METODOLÓGICA}

Quanto à metodologia empregada, deve-se destacar que, ante a vastidão do tema na doutrina nacional, optou-se por tomar como ponto de partida o trabalho do Professor Fernando Dias Menezes de Almeida, que orientou o candidato que subscreve a presente tese, e com o qual obteve o título de Livre-Docente em Direito Administrativo por esta Faculdade de Direito, no ano de 2010, e que foi publicada comercialmente em 2012, com o título Contrato Administrativo ${ }^{4}$.

A opção por esta forma de abordagem decorre da profundidade com que o tema do contrato administrativo foi tratado no mencionado trabalho. A pesquisa de Fernando Dias Menezes de Almeida deu-se a partir de fontes originárias, revelando um trabalho primoroso, que permitiu ao autor organizar e sistematizar informações até então dispersas, ao menos na literatura nacional, e algumas delas até ocultas, em virtude da predileção dos estudiosos brasileiros por determinados autores franceses, em detrimento de outros.

O esforço empreendido pelo autor citado, no sentido de mapear as gêneses do que se convencionou chamar de contrato administrativo, e os correspondentes comentários da doutrina francesa e brasileira sobre o tema, foi acompanhado do necessário exame de aderência entre as origens do conceito de contrato administrativo, e dos correspondentes debates teóricos sobre ele, à realidade brasileira.

Uma grande contribuição do mencionado trabalho doutrinário, particularmente para o tema desta tese, é justamente a constatação de que a doutrina e a legislação nacionais distanciaram-se das raízes do instituto, gerando uma aparente confusão, que acabou por transformar qualquer contrato de que a Administração Pública participasse num contrato administrativo, com efeitos prejudiciais à compreensão do tema e, principalmente, para a experiência prática envolvendo os contratos administrativos.

Há de se anotar que a presente tese não sugere a prevalência da doutrina sobre o direito legislado, mas não se olvida, contudo, o peso da doutrina do direito administrativo

\footnotetext{
${ }^{4}$ Fernando Dias Menezes de Almeida. Contrato Administrativo. São Paulo: Quartier Latin, $1^{\text {a }}$ ed., 2012
} 
na positivação de muitos de seus institutos, inclusive o dos contratos administrativos, no qual se insere o direito ao equilíbrio econômico-financeiro.

Nesse quadro, a presente tese de doutoramento procura dar sequência a esse aspecto específico, primeiramente apontado no trabalho de Fernando Dias Menezes de Almeida, que é o do descasamento entre a evolução teórica do instituto, sua conceituação, e a experiência brasileira, sobretudo na doutrina e na legislação. Em especial, a presente tese abordará, sob o prisma teórico, a garantia do equilíbrio econômico-financeiro em contratos administrativos de concessão de serviços públicos.

A partir das lições de Fernando Dias Menezes de Almeida, que embasam este estudo, especialmente quanto às origens francesas do conceito de contrato administrativo e do direito ao equilíbrio econômico-financeiro, a tese procurou abordar as colaborações de autores nacionais selecionados que se dedicaram a este último tema, sem expô-las de modo exaustivo.

Nesse sentido, a opção foi a de trabalhar com dois autores nacionais mais antigos, ou "clássicos", e que em muito se aproximavam da contribuição francesa originária, bem destacada na obra de referência de Fernando Dias Menezes de Almeida. Esses dois autores são Francisco Campos e Caio Tácito, que, no seu tempo, desempenharam papel relevante na doutrina e na burocracia estatal, ocupando posições ideológicas distintas - o que inibe o risco de o trabalho valer-se erroneamente de uma determinada tendência de pensamento. Afora isso, deve-se também anotar que esses dois autores contribuem para as proposições da tese, listadas acima.

Para ilustrar a compreensão atualmente vigente sobre o direito ao equilíbrio econômico-financeiro, a tese se valeu de dois autores contemporâneos: Carlos Ari Sundfeld e Marçal Justen Filho. A ideia ao se referir a eles foi a de compreender como a doutrina atual entende o direito ao equilíbrio econômico-financeiro nos contratos regidos pela lei de licitações.

Além dos autores acima mencionados, o presente trabalho recorreu a quatro outros autores. 
Em artigo escrito conjuntamente, Floriano de Azevedo Marques Neto e Carlos Eduardo $\mathrm{Cunha}^{5}$ parecem compreender o direito ao equilíbrio econômico-financeiro de modo absolutamente diverso do que é sustentado por esta tese, que, acredita-se, está em harmonia com a concepção originalmente conferida ao instituto pelos comentadores franceses e pelos autores clássicos acima indicados. Por essa razão, mencionado trabalho recebeu atenção especial neste estudo.

Os ensinamentos de Marcos Augusto Perez, por sua vez, foram objeto de estudo em razão de sua preocupação com a necessidade de se adequar a compreensão das noções sobre contratos administrativos em face da experiência contratual verificada a partir da segunda metade dos anos 1990.

Finalmente, a tese adotou as lições de Egon Bockmann Moreira ${ }^{6}$ para apoiar algumas de suas proposições. Em artigo relativamente recente, o autor sustenta que o artigo 65 da lei de licitações não se aplicaria aos contratos de concessão. Esse dispositivo legal tratou, entre outras providências, do direito ao equilíbrio econômico-financeiro.

Deve-se reconhecer que a tese se valeu de número reduzido de autores. Todavia, essa escolha mostra-se justificável ante o fato de existir certo consenso na literatura nacional sobre o tema do equilíbrio econômico-financeiro. Desse modo, os autores acima indicados servem como referência paradigmática, para os fins desta tese, de um conjunto mais amplo de visões e contribuições.

O trabalho está dividido em 5 (cinco) capítulos, além desta introdução e das conclusões finais.

No capítulo 1, analisa-se o itinerário histórico da formação da concepção teórica de contrato administrativo, tanto na França quanto no Brasil, com a finalidade de apontar para a influência francesa na concepção brasileira do instituto.

\footnotetext{
${ }^{5}$ Floriano de Azevedo Marques Neto e Carlos Eduardo Cunha. "O equilíbrio econômico-financeiro nos contratos administrativos de concessão rodoviária e o caso dos riscos inseguráveis" in Direito Econômico Atual, Diogo R. Coutinho, Jean-Paul Veiga da Rocha e Mario G. Schapiro. Ed. Forense/Ed. Método, 2015 , pp.: 19-40.

6 Egon Bockmann Moreira, "Contratos Administrativos de longo prazo e a lógica de seu equilíbrio econômico-financeiro" in Contratos Administrativos, Equilíbrio Econômico e Financeiro e a Taxa Interna de Retorno, Egon Bockmann Moreira (org.). Belo Horizonte: Fórum, 2016, pp.: 79-88.
} 
No segundo capítulo, expõe-se a forma como a teoria francesa do contrato administrativo foi implantada no Brasil, tanto pelo legislador quanto pela doutrina. Analisam-se, em especial, as duas características mais marcantes de tal tipo contratual: a sua mutabilidade e a manutenção do equilíbrio econômico-financeiro do contrato.

No terceiro capítulo, analisam-se a construção teórica e o tratamento atual do tema do equilíbrio econômico-financeiro no Brasil. Partindo da construção histórica de tal teoria, demonstrando ser ela caudatária da construção francesa dos contratos de concessão de serviços públicos. A partir do estudo dos autores acima mencionados será possível analisar como a teoria foi construída e difundida no Brasil, tanto antes quanto depois da entrada em vigor da lei de licitações e da lei de concessões. O capítulo pretende analisar como o conteúdo do direito ao equilíbrio econômico-financeiro foi elaborado em sua formação e como tem sido neste momento.

No capítulo 4, será proposta uma releitura teórica do instituto do equilíbrio econômico-financeiro do contrato administrativo, especialmente do contrato de concessão de serviços públicos. A intenção é a de demonstrar a impossibilidade de aplicação do artigo 65, inciso II, alínea 'd' da lei de licitações, aos contratos de concessão, uma vez que as lógicas contratuais são diversas e a própria dinamicidade destes contratos demanda que as medidas aptas ao seu reequilíbrio sejam tomadas de acordo com métodos e análises distintos dos aplicáveis aos contratos regidos pela lei de licitações.

No capítulo 5, será exposto o caso dos termos aditivos dos contratos de concessão de rodovia do Estado de São Paulo, com a finalidade de ilustrar as limitações existentes na aplicação do tratamento que a doutrina majoritária confere ao direito ao equilíbrio econômico-financeiro nos contratos de concessão, bem como a necessidade de que se reconheçam às partes condições jurídicas para a repactuação da avenca, nas hipóteses em que o evento de desequilíbrio contratual seja decorrente da teoria da imprevisão ou cujos efeitos se mostrem permanentes e cambiantes ao longo do contrato, como a criação ou a majoração de tributos. 


\section{CONCLUSÃO}

Conforme exposto na introdução, o objetivo deste trabalho foi o de lançar novas luzes para o tradicional tema do equilíbrio econômico-financeiro dos contratos administrativos, em especial dos contratos de concessão de serviços públicos.

No capítulo 1, analisou-se o itinerário histórico da formação da concepção de contrato administrativo, tanto na França como no Brasil. Neste passou, restou demonstrado que a noção brasileira de contrato administrativo é fruto da concepção francesa, formada pelo Conselho de Estado, no início do século XX, a partir de aspectos pragmáticos ligados à necessidade de delimitação de sua própria competência jurisdicional, bem como ao tipo de atividade prestada em tais contratos, considerados serviços públicos - ainda que em uma concepção ampla.

Assim, a criação de um regime jurídico especial para os contratos públicos, especial em relação o regime privado aplicável aos contratos firmados entre particulares, possuía dois aspectos funcionais: ao mesmo tempo em que permitia ao Conselho de Estado fixar a sua competência, reconhecia à Administração o exercício de suas competências, inerentes ao serviço publico, ainda que em detrimento da estabilidade do vinculo, mas não em prejuízo do particular.

Partindo desta base, os doutrinadores e a legislação brasileiros passaram a construir uma teoria nacional do contrato administrativo - tema abordado no capítulo 2 -, que, no entanto, foi expandida, para todos os tipos de contratos celebrados pela Administração. Prevaleceu o aspecto estrutural sobre o funcional, de modo que, a qualquer tipo de objeto contratado pela Administração, passou a incidir o regime especial. Como medida apta a tutelar os interesses patrimoniais do contratado, em face desse regime especial, tanto a doutrina quanto a legislação fixaram a manutenção do equilíbrio econômico-financeiro do contrato como garantia do contratado.

No terceiro capítulo, foram analisados a construção histórica e o tratamento atual do tema do equilíbrio econômico-financeiro no Brasil. No primeiro momento, foi analisada a construção histórica de tal teoria, demonstrando ser ela caudatária da construção francesa dos contratos de concessão de serviços públicos. No segundo momento, foram analisados autores mais recentes, que tiveram sua produção acadêmica realizada no período posterior 
à edição da Lei 8.666/93. Finalmente, foram estudados os principais autores que trataram deste tema em contratos de concessão de serviços públicos, de acordo com a Lei 8.987/95. Dessa análise, foi possível perceber que parte relevante da doutrina brasileira entende aplicável aos contratos de concessão de serviços públicos os artigos 37, inciso XXI, da Constituição Federal, e o artigo 65, inciso II, alínea $d$, da lei de licitações. Desse modo, a ocorrência de evento abrangido pela teoria da imprevisão, compreendida no referido dispositivo legal, enseja o reequilíbrio contratual, em beneficio do particular contratado.

No capítulo 4, realizou-se parcela da proposta desta tese, no sentido de propor uma releitura para o instituto do equilíbrio econômico-financeiro do contrato administrativo, especialmente do contrato de concessão de serviços públicos. Após apontar a insuficiência do tratamento legislativo do tema, referendou-se a impossibilidade de aplicação do artigo 65, da Lei 8.666/93 aos contratos de concessão, em especial, de seu inciso II, alínea $d$, uma vez que as lógicas contratuais são diversas e a própria dinamicidade destes contratos demanda que as medidas aptas a reequilibra-los sejam tomadas de acordo com métodos e análises específicas.

No capítulo 5, foi analisado o polêmico caso dos termos aditivos dos contratos de concessão de rodovia do Estado de São Paulo, no qual foi demonstrada a tese aqui defendida, no sentido de que

(a) A garantia ao equilíbrio econômico-financeiro presta-se a proteger o particular contratado de consequências deletérias decorrentes do exercício efetivo dos poderes especiais pela Administração, enquanto parte da relação contratual. Para além disso, quanto muito, a garantia ao equilíbrio econômico-financeiro serve para proteger o particular contratado da ocorrência de fatos extracontratuais, porém, provocados pela Administração para, produzindo efeitos concretos, alterar o modo de ser do objeto serviço público originalmente contratado. Nesse sentido, eventos abrangidos pela teoria da imprevisão ou considerados como de força maior não são passíveis de reequilíbrio econômico-financeiro - mas devem dar ensejo à repactuação do contrato, conforme exposto a seguir.

(b) Falar-se em equilíbrio econômico-financeiro para contratos administrativos regidos pela lei de licitações não é o mesmo que se falar em equilíbrio econômico-financeiro para contratos de concessão de serviços públicos, o 
que impacta na extensão do direito ao equilíbrio econômico-financeiro num e noutro caso.

(c) A ocorrência de eventos extracontratuais, abrangidos pela teoria da imprevisão ou de força maior, e que impactem o equilíbrio econômico-financeiro inicial da avença, pode inviabilizar o seu restabelecimento. Nesses casos, falar-se em reequilíbrio econômico-financeiro é uma imprecisão técnica, admitida, contudo, em razão da sedimentação de seu uso para essa finalidade.

(d) A superveniência de alterações tributárias pode não dar ensejo ao exercício do direito ao equilíbrio econômico-financeiro do contrato, exceto se decorrente de ato de efeitos concretos sobre o objeto serviço público que constitui o objeto do contrato de concessão, como exposto no primeiro tópico. Alterações tributárias de efeitos abstratos, que porventura afetem os custos contratuais, não se equiparam ao exercício de poderes especiais pela Administração enquanto parte contratual. Ademais, é equivocado supor que a Administração contratante necessariamente dispõe de instrumentos ou poderes para influenciar, de modo direto, alterações tributárias de competência legislativa diversa com o fim de obter benefícios econômico-financeiros extracontratuais do particular com quem contrata.

Após essas considerações, parece possível afirmar que, no contrato administrativo, o particular aceita e se submete, voluntariamente, ao exercício de poderes especiais, pela Administração, limitados estes a "assegurar o funcionamento regular e contínuo do serviço público com o qual consentiu em colaborar" ${ }^{289}$. Vê-se, aqui, que esses poderes especiais da Administração se limitam ao objeto serviço público, e não a todo o conteúdo do contrato, ainda que, ao exercê-los, termine eventualmente por alterar, por exemplo, a parte econômica do contrato, devendo de algum modo restabelecê-la.

É possível sumarizar as conclusões desta tese, nos seguintes termos:

(i) No contrato de concessão de serviço público, afirmar-se que equilíbrio econômico-financeiro é manutenção das condições da proposta, nos termos do

\footnotetext{
${ }^{289}$ Gaston Jèze. "Théorie Générale des Contrats de l'Administration" in Revue du Droit Public et de la Science Politique em France et à l'Étranger. Anées 1930 a 1936. Paris: Marcel Giard, 1930 ; Paris: Librairie Générale de Droit et de Jurisprudence, 1934 a 1936, pp.: 683 apud Fernando Dias Menezes de Almeida. Contrato Administrativo. São Paulo: Quartier Latin, $1^{\text {a }}$ ed., 2012, pp.: 146.
} 
artigo 37, XXI, da Constituição Federal, ou que ele significa o atendimento às condições do contrato, conforme o artigo 10 da Lei 8.987/95, não significa nada de concreto, uma vez que é necessário compreender o equilíbrio contratual dentro da sua dinâmica e mutação ao longo dos anos. Este argumento encontra eco na análise do caso dos termos modificativos dos contratos de concessão rodoviária, uma vez que a interpretação da majoração tributária de acordo com estes dispositivos levou à divergência entre as partes, amplificando os conflitos entre as partes;

(ii) A determinação do equilíbrio contratual é determinada pelo próprio contrato, devendo ser analisada no momento em que ocorrer o evento que desequilibrar a avença. Assim, a lei deve deixar espaço para que o contrato preveja mecanismos de negociações entre as partes para o estabelecimento de repactuação, na qual, em determinados casos, os prejuízos sejam suportados pelas partes, como materialização de riscos não previstos contratualmente e não decorrentes de ação direta da Administração sobre o contrato;

(iii) Ao invés de repetir a regra geral, transformada em mantra, de que o equilíbrio econômico-financeiro é a manutenção das condições da proposta, devemos reconhecer a complexidade destes contratos e aprimorá-los, no sentido de que eles prevejam mecanismos de repactuação da avença, nos casos aqui mencionados. 


\section{BIBLIOGRAFIA}

ALMEIDA, Fernando Dias Menezes de. Contrato Administrativo. $1^{\text {a }}$ ed., São Paulo: Quartier Latin, 2012.

. "Contratos Administrativos no Brasil - Aspectos críticos da teoria e da prática", in Revista de Contratos Públicos - RCP, n. 1. Belo Horizonte: Fórum, mar./ago. 2012, pp.: 125/139.

Formação da Teoria do Direito Administrativo no Brasil. $1^{\mathrm{a}}$ ed., São Paulo: Quartier Latin, 2015.

; JURKSAITIS, Guilherme Jardim. "O sentido 'contratual' do contrato administrativo: aspecto da jurisprudência do STF analisado sob a luz do pensamento de Celso Antônio Bandeira de Mello", in CAMMAROSANO, Márcio; ZOCKUN, Maurício; PEREIRA, Flávio Unes; SILVEIRA, Marilda (org.). $O$ direito administrativo na jurisprudência do STF e do STJ. Belo Horizonte: Fórum, 2014, pp.: 235-242.

ANKER, Tomas; e TUROLLA, Frederico. "Desequilíbrio econômico-financeiro em contratos de participação privada de longo prazo", in SUNDFELD, Carlos Ari; JURKSAITIS, Guilherme Jardim (org.). Contratos públicos $e$ direito administrativo. São Paulo: Malheiros, 2015, pp.: 237-255.

BANDEIRA DE MELlO, Celso Antônio. Curso de Direito Administrativo. $27^{a}$ ed., São Paulo: Malheiros, 2010.

Elementos de Direito Administrativo. São Paulo: Revista dos Tribunais, 1980.

Natureza e Regime Jurídico das Autarquias. São Paulo, Revista dos Tribunais, 1968 
BANDEIRA DE MELLO, Osvaldo Aranha. Princípios Gerais de Direito Administrativo. Vol. I. Rio de Janeiro: Forense, 1968.

CAMPOS, Francisco. Direito Administrativo. Rio de Janeiro: Imprensa Nacional, 1943.

Direito Administrativo. Vol. I. e Vol. II. Rio de Janeiro: Freitas Bastos S.A., 1958.

CAVALCANTI, Themístocles Brandão. Curso de Direito Administrativo. $8^{\mathrm{a}}$ ed., São Paulo: Atlas, 1967.

DI PIETRO, Maria Sylvia Zanella. "500 Anos de Direito Administrativo Brasileiro". In Revista Brasileira de Direito Público - RBDP. Belo Horizonte, n. 1, ano 1, Abril I Junho 2003.2 Disponível em: <http://www.bidforum.com.br/PDI0006.aspx?pdiCntd=12514>, acesso em: 3 de maio de 2019.

. Parcerias na Administração Pública. 10ª ed., São Paulo: Atlas, 2015.

ENEI, José Virgílio Lopes. Project finance: financiamento com foco em empreendimentos: (parecerias público-privadas, leveraged buy-outs e outras figuras afins). São Paulo: Saraiva, 2007.

DUGUIT, Léon. L'État, le Droit Objectif et la Loi Positive. Paris: Dalloz, 2003 (edição facsimilar de Paris: Fontemoing, 1901).

ENTERRÍA, Eduardo García de; FERNÁNDEZ, Tomás-Ramón. Curso de Direito Administrativo, Vol. 1. $1^{\text {a }}$ edição traduzida a partir da $16^{\mathrm{a}}$ edição espanhola, de 2013, por José Alberto Froes Cal, com revisão técnica de Carlos Ari Sundfeld. São Paulo: Thomson Reuters, 2014.

FIGUEIREDO, Lúcia Valle. Curso de Direito Administrativo. $6^{\mathrm{a}}$ ed., São Paulo: Malheiros, 2003. 
FOLHA DE SÃO PAULO. “Concessão de rodovias gerou ganho indevido de $\mathrm{R} \$ 2 \mathrm{Bi}$, diz ARTESP”. Edição de 17/07/2013. Disponível em [http://www1.folha.uol.com.br/cotidiano/2013/07/1313376-auditoria-diz-queconcessionarias-de-sp-tiveram-ganho-indevido-de-r-2-bilhoes.shtml], acesso em $3 / 5 / 2019$.

GROTTI, Dinorá Adelaide Musetti. O serviço público e a Constituição brasileira de 1988. São Paulo: Malheiros, 2003.

GUIMARÃES, Fernando Vernalha. Concessão de serviço público. São Paulo: Saraiva, 2012.

. "O equilíbrio econômico-financeiro nas concessões e PPPS: formação e metodologia para recomposição", in Egon Bockmann Moreira. (Org.). Contratos Administrativos, Equilíbrio Econômico e Financeiro e a Taxa Interna de Retorno. Belo Horizonte: Fórum, 2016, pp.: 89-108.

HAURIOU, Maurice. Précis de Droit Administratif et de Droit Public. Paris: Dalloz, 2002 (edição facsimilar de Paris: Sirey, 1933, 12a ed.).

JURKSAITIS, Guilherme Jardim. "Uma proposta para melhorar os aditamentos a contratos públicos”, in SUNDFELD, Carlos Ari; JURKSAITIS, Guilherme Jardim (org.). Contratos públicos e direito administrativo. São Paulo: Malheiros, 2015, pp.: 277294.

JUSTEN FILHO, Marçal. Comentários à lei de licitações e contratos administrativos. $12^{\mathrm{a}}$ ed. São Paulo: Dialética, 2006.

. Comentários à lei de licitações e contratos administrativos. $16^{\mathrm{a}}$ ed. São Paulo: Revista dos Tribunais, 2014.

. Teoria geral das concessões de serviço público. São Paulo: Dialética, 2003. 
LONG, Marceau; WEIL, Prosper; BRAIBANT, Guy; DEVOLVÉ, Pierre; GENEVOIS, Bruno. Les Grands Arrêts de la Jurisprudence Administrative. Paris: Dalloz, 1996.

MARQUES NETO, Floriano de Azevedo; CUNHA, Carlos Eduardo. "O equilíbrio econômico-financeiro nos contratos administrativos de concessão rodoviária e o caso dos riscos inseguráveis", in COUTINHO, Diogo R.; ROCHA, Jean-Paul Veiga da; SCHAPIRO, Mario G. (Coords.). Direito Econômico Atual. Rio de Janeiro: Ed. Forense / São Paulo: Ed. Método, 2015, pp.: 19-40.

MEDAUAR, Odete. Direito administrativo moderno. $20^{\mathrm{a}}$ ed., São Paulo: Revista dos Tribunais, 2016.

MOREIRA, Egon Bockmann. "Contratos Administrativos de longo prazo e a lógica de seu equilíbrio econômico-financeiro", in Egon Bockmann Moreira (Org.). Contratos Administrativos, Equilíbrio Econômico e Financeiro e a Taxa Interna de Retorno. Belo Horizonte: Fórum, 2016, pp.: 79-88.

Direito das Concessões de Serviço Público - Inteligência da Lei 8.987/1995 (Parte Geral). São Paulo: Malheiros, 2010.

PEREZ, Marcos Augusto. O risco no contrato de concessão de serviços públicos. Tese de doutorado apresentada à Faculdade de Direito da Universidade de São Paulo. São Paulo, 2005, 243 fls.

. O Risco no contrato de concessão. Belo Horizonte: Fórum, 2006.

RIBEIRO, Maurício Portugal. Apresentação disponível em [http://pt.slideshare.net/portugalribeiro/o-equilbrio-econmicofinanceiro-deconcesses-e-ppps-e-a-sua-prtica-compensatria?related=2], slide 6. Acesso em 26/3/2019.

SCHIRATO, Vitor Rhein. "Concessões de serviços públicos e investimentos em infraestrutura no Brasil: espetáculo ou realidade?", in SUNDFELD, Carlos Ari; JURKSAITIS, Guilherme Jardim (org.). Contratos públicos e direito administrativo. São Paulo: Malheiros, 2015, pp.: 142-169. 
SCHWIND, Rafael Wallbach. Remuneração do concessionário: concessões comuns e parcerias público-privadas. Belo Horizonte: Fórum, 2010.

SOUSA, Paulino José Soares de (Visconde do Uruguai). "Ensaio sobre o Direito Administrativo", in CARVALHO, José Murilo de. (Org.) Paulino José Soares de Sousa: Visconde do Uruguai. São Paulo: Editora 34, 2002.

SUNDFELD, Carlos Ari. Fundamentos de Direito Público. $2^{\mathrm{a}}$ ed. São Paulo: Malheiros, 1996.

Licitação e contrato administrativo. $2^{\text {a }}$ ed., São Paulo: Malheiros, 1995.

. "Risco de tráfego e equilíbrio econômico-financeiro da concessão de rodovia"; in Pareceres, Vol. II. São Paulo: Thomson Reuters Revista dos Tribunais, 2013, pp.: 21-33.

; CÂMARA, Jacintho Arruda. "Uma crítica à tendência de uniformizar com princípios o regime jurídico dos contratos administrativo" in Revista de Direito Público da Economia - RDPE. Belo Horizonte: Fórum, jan./mar. 2013, pp.: 57-72.

; _ _ SOUZA, Rodrigo Pagani de. "Concessão de serviço público: limites, condições e consequências da ampliação dos encargos da concessionária" in OLIVEIRA, Farlei Martins Riccio de (Coord,). Direito Administrativo Brasil - Argentina: estudos em homenagem a Agustín Gordillo. Belo Horizonte: Del Rey, 2007, pp.: 24-44.

TÁCITO, Caio. O equilíbrio financeiro na concessão de serviço público. Mimeo. Rio de Janeiro: [s.n.], 1960. $126 \mathrm{f}$.

" "O equilíbrio financeiro na concessão de serviço público" in Revista de Direito Administrativo, vol. 64. Rio de Janeiro: Fundação Getúlio Vargas do Estado do Rio de Janeiro, 1961, pp.: 15-35. 